\title{
Correction to: Voriconazole-induced periostitis in stem cell transplant patient
}

\author{
Alexandre E. Malek ${ }^{1,2} \cdot$ Yara Skaff $^{3} \cdot$ Victor E. Mulanovich $^{1}$
}

Published online: 19 June 2020

○) Springer-Verlag GmbH Germany, part of Springer Nature 2020

\section{Correction to: Infection}

https://doi.org/10.1007/s15010-020-01445-0

The original version of this article unfortunately contained a mistake. The spelling of Yara Skaff's name was incorrect. The corrected author list is given above.

The original article has been corrected.

The original article can be found online at https://doi.org/10.1007/ s15010-020-01445-0.

Alexandre E. Malek

alexandre.e.malek@uth.tmc.edu

1 Department of Infectious Diseases, Infection Control and Employee Health, The University of Texas MD Anderson Cancer Center, 1515 Holcombe Boulevard, Houston, TX 77030, USA

2 Division of Infectious Diseases, Department of Internal Medicine, McGovern Medical School, University of Texas Health Science Center At Houston, Houston, TX, USA

3 Department of Internal Medicine, The Gilbert and Rose-Marie Chagoury School of Medicine, Lebanese American University, Beirut, Lebanon 